\title{
Hydrogel Dressings for Advanced Wound Management
}

\author{
Antonio Francesko ${ }^{\mathrm{a}}$, Petya Petkova ${ }^{\mathrm{b}}$, Tzanko Tzanov ${ }^{* \mathrm{~b}}$ \\ (The author will be required to provide their full names, the institutional affiliations and the location, with an asterisk in front of the name \\ of the principal/corresponding author). \\ ${ }^{a}$ Centro de Física, Universidade do Minho, 4710-057, Braga, Portugal \\ b Grup de Biotecnologia Molecular i Industrial, Department of Chemical Engineering, Universitat \\ Politècnica de Catalunya, Terrassa, Spain
}

\begin{abstract}
Composed in a large extent of water and due to their non-adhesiveness, hydrogels found their way to the wound dressing market as materials that provide a moisture environment for healing while being comfortable to the patient. Hydrogels' exploitation is constantly increasing after evidences of their even broader therapeutic potential due to resemblance to dermal tissue and ability to induce partial skin regeneration. The innovation in advanced wound care is further directed to the development of so-called active dressings, where hydrogels are combined with components that enhance the primary purpose of providing a beneficial environment for wound healing. The aim of this mini-review is to concisely describe the relevance of hydrogel dressings as platforms for delivery of active molecules for improved management of difficult-to-treat wounds. The emphasis is on the most recent advances in development of stimuli-responsive hydrogels, which allow for control over wound healing efficiency in response to different external modalities. Novel strategies for monitoring of the wound status and healing progress based on incorporation of sensor molecules into the hydrogel platforms are also discussed.
\end{abstract}

Keywords: hydrogels; stimuli-responsiveness; sensor molecules; smart polymers; wound healing; wound monitoring

\section{INTRODUCTION}

Except for deep wounds and large surface wounds, wounded skin is expected to heal within a reasonable period of time through a series of regulated events. However, when this process is interrupted in any of the healing stages, wounds fail to heal in the normal time window and become chronic or non-healing wounds. A variety of treatments have been attempted for non-healing wounds, however many wounds still do not respond to the available treatment modalities and represent a big societal and clinical burden ${ }^{1}$. For instance, chronic wounds are a global cause for morbidity and the primary cause for non-traumatic amputation ${ }^{2}$. Wound infection is another difficult-to-treat complication in non-healing wounds that has to be efficiently managed prior to or during the wound closure ${ }^{3}$.

Any "passive" treatment directed to provide healingbeneficial conditions, without targeting repair of these vital functions, is unlikely to substantially increase the healing rate of such ulcers. Moreover, the incidence of non-healing wounds is constantly increasing due to lifestyle changes and the aging population worldwide. The efficient management of chronic wounds is further compromised by their complexity, subjectivity of the healing process and patient variability. In this scenario, advanced treatment strategies are essential to reduce the morbidity rates associated to nonhealing wounds.
A straightforward way to achieve this goal is the development of multifunctional wound dressing materials able to simultaneously address different aspects of the wound healing process. Novel dressing materials are thus constantly being investigated. Their capability to achieve rapid healing at reasonable cost coupled with minimal inconvenience to the patients is a common targeted feature.

\footnotetext{
*Address correspondence to this author at the Department of Chemical Engineering, Universitat Politècnica de Catalunya, P.O. Box: 08222, Terrassa, Spain; Tel: +34937398570, Fax: +34937398225; E-mail: tzanko.tzanov@upc.edu
}

This review summarises the progress in the development of hydrogel-based dressings bearing advanced functions for accelerated wound healing. Key properties and mechanisms of the dressings efficiency are outlined. These combine the intrinsic healing potential of the hydrogel platforms based on the maintenance of wound moisture and added multiple functionalities for initiation, enhancement and screening of wound healing. In particular, stimuli-responsive hydrogels as well as the dressings designed for monitoring of the healing progress are discussed. Dressings at different stages of development are considered - from experimental scenarios, to those in early and late clinical stages. The focus of the review is on the performance of the advanced dressings, while the gel forming polymers are reviewed elsewhere ${ }^{4-7}$. The specifics of the dressing's application - should it be 
removed/changed once the healing is stimulated/completed or should it stay in the wound bed as a source of active ingredients, are not discussed herein.

\section{Hydrogels and their properties for wound healing}

Hydrogels owe their large use as wound dressings to the peculiar combination of high water content, softness, flexibility and biocompatibility. Besides providing a beneficial for the healing moisture environment, hydrogels are comfortable and easy-to-change materials with pain alleviating effect for the wounded tissue. Wound temperature is decreased by hydrogels, whereas their high water content aids soothing the wounded area, particularly important in the treatment of dry wounds. On the other hand, the hydrogels absorb the wound exudate and maintain it away from the wound bed. Hydrogels are defined as suitable for all four stages of the healing process (haemostasis, inflammation, cell migration/proliferation, and maturation) of a wide range of wounds because they are non-irritant, non-reactive with biological tissue and ideally permeable to metabolites. The enormous variety of hydrogel dressings matches the requirement for optimisation of wound treatments applying the right dressing to a particular wound. These advantageous features of hydrogels allowed their fast entrance in the dressing market where hydrogels are available as sheets, saturated gauze or gels ${ }^{8}$.

In 1960 Wichterle and Lím suggested the use of hydrophilic gels for extended contact with living tissues ${ }^{9}$ which found application in numerous biomedical applications. The potential of polymeric hydrogels to assist in wound healing is increasingly investigated in laboratory and clinical settings from the early 80s and was firstly based only on the intrinsic properties of natural polymers, such as polysaccharides and proteins. For example, chitin and chitosan gel-like materials were recognised as excellent candidates for dressings development because of their appealing biological activities and wound healing accelerators ${ }^{10-12}$. In parallel, the research was focused on structural proteins, i.e. collagen, in particular regarding cellular function, migration, proliferation and differentiation in such gels, necessary for wound epithelialization ${ }^{13-15}$. The investigation rapidly expanded also towards biocompatible synthetic polymers as the mechanical properties of the resulting hydrogels can be easily tuned ${ }^{16,17}$. As a result, hydrogel dressings are extensively researched for accelerated wound healing and platforms for monitoring of the healing process, while some of the dressings are commercially available in the form of amorphous gels, gel-impregnated gauzes, sheets or plasters, the latter in combination with a variety of adhesives and bandages.

All hydrogels are produced by physical or chemical cross-linking of natural and/or synthetic hydrophilic polymers. The variable stability and nature of the interactions between the gel macromolecules define their capacity to retain water (moisture) in the hydrogel network. Also, the cross-linked structure prevents rapid dissolution of the material and provides mechanical stability and durability at use leading to less frequent dressing changes. In addition, hydrogels may absorb and release water in a reversible manner in response to physiological stimuli, allowing for smart function control ${ }^{5,6,18}$. A summary of the most commonly used in hydrogels polymers for acceleration of wound healing is given in Table 1 (natural polymers) and Table 2 (synthetic polymers).

Table 1 Summary of commonly employed natural polymers used for hydrogel preparation and their function in wound management

\begin{tabular}{|c|c|c|c|}
\hline $\begin{array}{l}\text { Main } \\
\text { polymer }\end{array}$ & Properties & $\begin{array}{l}\text { Function in } \\
\text { wounds }\end{array}$ & Reference \\
\hline Alginate & $\begin{array}{l}\text { Wound dressing, } \\
\text { Ease } \\
\text { application, } \\
\text { conformability, } \\
\text { Biodegradability }\end{array}$ & $\begin{array}{l}\text { Healing promotion, } \\
\text { Infection control, } \\
\text { Haemostatic effect }\end{array}$ & $19-21$ \\
\hline Chitosan & $\begin{array}{l}\text { Wound dressing, } \\
\text { In situ gelation, } \\
\text { Biodegradability }\end{array}$ & $\begin{array}{l}\text { Healing promotion, } \\
\text { Infection control, } \\
\text { Anti-inflammatory } \\
\text { effect, Haemostatic } \\
\text { effect, Delivery of } \\
\text { active molecules, } \\
\text { Monitoring healing } \\
\text { progress }\end{array}$ & 22-29 \\
\hline Gelatin & $\begin{array}{l}\text { In situ gelation, } \\
\text { Conformability, } \\
\text { Biodegradability }\end{array}$ & $\begin{array}{l}\text { Delivery of active } \\
\text { molecules, } \\
\text { Tissue } \\
\text { reinforcement, Cell } \\
\text { recruitment }\end{array}$ & \begin{tabular}{|l|}
$21,24,30,31$ \\
\end{tabular} \\
\hline Collagen & $\begin{array}{l}\text { Wound dressing, } \\
\text { In situ gelation, } \\
\text { Biodegradability }\end{array}$ & $\begin{array}{l}\text { Delivery of active } \\
\text { molecules, } \\
\text { Tissue } \\
\text { reinforcement, Cell } \\
\text { support }\end{array}$ & 32-34 \\
\hline Dextran & Skin substitute & $\begin{array}{l}\text { Healing promotion, } \\
\text { Delivery of active } \\
\text { molecules }\end{array}$ & 35 \\
\hline Cellulose & Moisture control & $\begin{array}{l}\text { Healing promotion, } \\
\text { Cell support }\end{array}$ & 36 \\
\hline Heparin & $\begin{array}{l}\text { Hydrogel sheet, } \\
\text { Moisture control }\end{array}$ & $\begin{array}{l}\text { Delivery of active } \\
\text { molecules }\end{array}$ & 37 \\
\hline $\begin{array}{l}\text { Glycosami } \\
\text { noglycans }\end{array}$ & $\begin{array}{l}\text { Film dressing, } \\
\text { Ointment, } \\
\text { Moisture control }\end{array}$ & $\begin{array}{l}\text { Infection control, } \\
\text { Tissue } \\
\text { reinforcement, } \\
\text { Guided tissue } \\
\text { regeneration, } \\
\begin{array}{l}\text { Promotion of } \\
\text { angiogenesis }\end{array}\end{array}$ & 38-41 \\
\hline
\end{tabular}




\begin{tabular}{|l|l|l|l|}
\hline $\begin{array}{l}\text { Mixed } \\
\text { extracellul } \\
\text { ar matrix } \\
\text { biopolymer }\end{array}$ & $\begin{array}{l}\text { Sprayable elastic } \\
\text { adhesive }\end{array}$ & $\begin{array}{l}\text { Wound closure, } \\
\text { Delivery of } \\
\text { antimicrobial } \\
\text { septides }\end{array}$ & \\
\hline
\end{tabular}

Table 2 Summary of commonly employed synthetic polymers used for hydrogel preparation and their function in wound management

\begin{tabular}{|c|c|c|c|}
\hline $\begin{array}{l}\text { Main } \\
\text { polymer }\end{array}$ & Properties & Function & Reference \\
\hline $\begin{array}{l}\text { Polyethy } \\
\text { lene } \\
\text { glycol }\end{array}$ & $\begin{array}{l}\text { Moisture } \\
\text { control }\end{array}$ & $\begin{array}{l}\text { Tissue support, Infection } \\
\text { control, } \\
\text { Delivery of active } \\
\text { molecules, } \\
\text { Cell adhesion }\end{array}$ & 43-46 \\
\hline $\begin{array}{l}\text { Polyviny } \\
\text { l alcohol }\end{array}$ & $\begin{array}{l}\text { Matrix } \\
\text { support, } \\
\text { Moisture } \\
\text { control, } \\
\text { Oxygen } \\
\text { transport }\end{array}$ & $\begin{array}{l}\text { Infection control, } \\
\begin{array}{l}\text { Delivery of active } \\
\text { molecules, }\end{array} \\
\begin{array}{l}\text { Monitoring } \\
\text { progress }\end{array}\end{array}$ & $28,43,47,48$ \\
\hline $\begin{array}{l}\text { Polyviny } \\
\text { l } \\
\text { pyrrolido } \\
\text { ne }\end{array}$ & $\begin{array}{l}\text { Topical } \\
\text { hydrogel- } \\
\text { based } \\
\text { formulation }\end{array}$ & $\begin{array}{l}\text { Wound healing via } \\
\text { microcirculation effect, } \\
\text { Antiseptic }\end{array}$ & 49,50 \\
\hline $\begin{array}{l}\text { Acrylic } \\
\text { polymers } \\
\text { (Carbop } \\
\text { ol) }\end{array}$ & $\begin{array}{l}\text { Oxygen } \\
\text { transport, } \\
\text { Matrix } \\
\text { support }\end{array}$ & $\begin{array}{l}\text { Delivery of antibiotics, } \\
\text { Cell adhesion }\end{array}$ & 51,52 \\
\hline $\begin{array}{l}\text { Polystyr } \\
\text { ene }\end{array}$ & $\begin{array}{l}\text { Wound } \\
\text { adhesive, } \\
\text { Moiture } \\
\text { control }\end{array}$ & $\begin{array}{l}\begin{array}{l}\text { Delivery } \\
\text { molecules }\end{array}\end{array}$ & 53 \\
\hline
\end{tabular}

To form a polymer hydrogel, different physical and chemical cross-linking strategies are employed. The physical cross-linking is achieved by changing the physical entanglement of the polymer chains or by non-covalent interactions such as hydrogen, ionic, or hydrophobic ones. The physical characteristics and mechanical properties of hydrogels can be modulated by changing $\mathrm{pH}$, ionic strength and temperature of gelation ${ }^{54,55}$. For example, the ionotropic gelation method for formation of cross-linked polysaccharides can be modified from ionic cross-linking to deprotonation by adjusting the $\mathrm{pH}$ of tripolyphosphate. In such conditions the polysaccharide ionic cross-linking takes place at lower $\mathrm{pH}$, while deprotonation occurs at higher $\mathrm{pH}$ ${ }^{43}$. The advantage of the physically cross-linked hydrogels lies in avoiding the need for chemical modification or the addition of cross-linking agents, which make them secure for in vivo applications. Such networks, however, are mechanically weak, resulting in fast erosion or degradation 56 . It is further difficult to control the material variables including gelation time, network pore size and degradation time, thus restricting also the design flexibility. A low viscosity liquid phase or syneresis of the hydrogel after the gel formation is another drawback of solely physical networks ${ }^{57}$.

A method that allows cross-linking without employing chemical linkers is the radiation-induced gelation of polymer-water systems ${ }^{58}$. Since the method aims at synthesis of hydrogels for biomedical applications it is worth mentioning that gel synthesis and sterilisation of the material are accomplished simultaneously in a single technological step. Though this subject was explored two decades ago, the well-established technology for gel manufacturing remained unchanged to date for development of functional hydrogels, such as chitosan-based ones with demonstrated antimicrobial properties ${ }^{59}$. Similar gelation/cross-linking is recently achieved by atmospheric dielectric barrier discharge plasma treatment where, importantly, gelation process does not negatively affect the chemical structure of biopolymers used for hydrogel preparation ${ }^{60}$.

On the other hand, chemically cross-linked networks are structures with high stability ensured by covalent bonds between the macromolecules. However, chemical crosslinking usually requires the addition of cross-linkers, or an additional step of polymer pre-activation (in case of the direct conjugation). The chemical cross-linking of hydrogels is advantageous in terms of better mechanical properties compared to the physically assembled materials. Nevertheless, residual chemicals and organic solvents employed for cross-linking may render them toxic to human cells ${ }^{61,62}$. Alternatively, covalently cross-linked gels could be obtain in situ via enzyme-catalysed reactions at mild process conditions and avoiding the use of harsh chemicals 63,64 . Materials obtained via an enzymatic cross-linking are fully exploitable as devices in contact with human tissues ${ }^{65}$.

Finally, a highly innovative approach for generation of hydrogels with desired properties are the supramolecular interactions. The prepared structures based on supramolecular self-assembly attracted special interest for biomedical applications due to the absence of toxic chemicals and the easiness of the assembling process. Other major reason is that such gels resemble the host tissues and the interactions with their constituting elements, i.e. structural proteins and glycosaminoglycans. For example, the supramolecular self-assembly of cyclodextrins and polymers has led to the development of novel supramolecular hydrogels for drug delivery applications. One such hydrogel suitable for relatively long-term sustained controlled release was formulated based on the complexation of $\alpha$-cyclodextrin with various triblock copolymers bearing a hydrophobic block ${ }^{66}$.

From a technological point of view, due to the availability of a wide spectrum of polymers and the 
accumulated knowledge in materials processing, the choice for fabrication of a hydrogel is defined by its particular application. For that reason, a great number of hydrogel dressings are commercially available for wound treatment, ranging from amorphous hydrogels for cavity wounds, to hybrid structures such as gel-impregnated plasters meant for the treatment of superficial wounds. In spite of the large number, there is still a need for the development of advanced materials that accelerate wound healing in relation to specific clinical applications. Uniquely, the therapeutic effect of the available products is imparted by the chemical nature of the hydrogel dressings and not by the supply of active substances into the wound bed. Therefore, the tendency is nowadays shifting to the development of multifunctional hydrogel systems that provide improved wound management via: i) control of infection ${ }^{67}$, ii) delivery of active molecules to the site of interest ${ }^{4,68}$ and/or iii) monitoring of the healing progress ${ }^{69}$. Such materials, though highly appealing, are still scarcely available at advanced investigation stages.

\section{Advanced hydrogel dressings}

\subsection{Hydrogels for delivery of active compounds in wounds}

\subsubsection{Simple delivery}

Advanced wound treatment is often based on controlled delivery of active substances into the wounded site. Many polymer-based dressings are employed as drug carriers due to their physical characteristics, e.g. fluid affinity, water uptake, rheological properties, and their suitability for delivery of therapeutics while maintaining the wound surfaces moist. In hydrogels, the extent of macromolecular cross-linking allows for tuning their physical, chemical and biological properties, which in the case of natural polymers is also coupled to their intrinsic biocompatibility and similarity with the extracellular matrix (ECM). Both the hydrogel porosity and the affinity to water are easily adjustable by controlling the density of cross-links. But it is maintaining of a high local concentration of the active ingredient over a long period that makes polymer hydrogels excellent platforms for drug delivery aiming at accelerated wound closure ${ }^{70,71}$. Their three-dimensional network enhances the cell attachment and migration ${ }^{72}$, and ECM deposition 73, while efficiently delivering bioactive molecules to the site of interest. Recent studies showed that hydrogels in swollen state simultaneously prevent bacteria entrance in the wound and allow the transport of the entrapped functional molecules to the wound bed ${ }^{71}$.

The most common molecules acting from hydrogels are antimicrobials ${ }^{74,75}$, proteins, peptides and growth factors ${ }^{76}$, as well as inhibitors of deleterious inflammatory enzymes found in non-healing ulcers ${ }^{77}$. The degradation of hydrogels is usually due to hydrolysis and/or enzymatic digestion upon infiltration of the inflammation-responding neutrophils into the gel matrix. The therapy optimisation consists in attaining a balance between hydrogel degradation and skin regeneration for each particular type of wound. A slower degradation is known to interfere with remodelling, whereas a fast one leads to premature dressing resorption ${ }^{78}$. Although the controlled delivery of actives from hydrogels is a complex wound healing approach subjected to slow transition from lab bench to clinic, it appears as an efficient strategy for rapid and full dermal regeneration.

Table 3 Commonly employed active compounds delivered from hydrogels for wound management

\begin{tabular}{|c|c|c|}
\hline Compound & Function & Reference \\
\hline $\begin{array}{l}\text { Dibutyryl cyclic } \\
\text { adenosine } \\
\text { monophosphate }\end{array}$ & $\begin{array}{l}\text { Accelerated healing, Re- } \\
\text { epithelialization }\end{array}$ & 20 \\
\hline Nitrofurazone & $\begin{array}{l}\text { Infection control, Accelerated } \\
\text { healing }\end{array}$ & 47 \\
\hline Antibiotics & Infection control & 51,79 \\
\hline Polyphenols & $\begin{array}{l}\text { Anti-inflammatory, } \\
\text { antibacterial and antioxidant effects }\end{array}$ & $64,80,81$ \\
\hline $\begin{array}{l}\text { Antimicrobial } \\
\text { peptide }\end{array}$ & $\begin{array}{l}\text { Infection control, Effect on immune } \\
\text { response }\end{array}$ & 42,82 \\
\hline Copper & $\begin{array}{l}\text { Infection control, Bacterial biofilm } \\
\text { inhibition }\end{array}$ & 46 \\
\hline $\begin{array}{l}\text { Silver } \\
\text { nanoparticles }\end{array}$ & Infection control & $25,83,84$ \\
\hline $\begin{array}{l}\mathrm{ZnO} \\
\text { nanoparticles }\end{array}$ & $\begin{array}{l}\text { Infection control, Bacterial biofilm } \\
\text { inhibition }\end{array}$ & 19,85 \\
\hline Growth factors & $\begin{array}{l}\text { Guided skin regeneration, } \\
\text { Accelerated healing }\end{array}$ & $35,86-88$ \\
\hline Stem cells & $\begin{array}{l}\text { Enhanced angiogenesis and cell } \\
\text { proliferation, Accelerated wound } \\
\text { closure, Guided skin regeneration }\end{array}$ & 89 \\
\hline
\end{tabular}

After discovering that the wound moist accelerates the healing, the second greatest technical advance adopted in clinical practice is the management of infections in wounds by the use of antimicrobials, mostly silver and iodine. The bacteria levels should be substantially reduced to initiate the healing process or to make possible the actuation of the actives, such as growth factors. Silver is currently established as the golden standard in fabrication of antimicrobial dressings due to its high effectiveness against a broad spectrum of microbes ${ }^{90,91}$ and low toxicity towards mammalian cells in low concentrations ${ }^{92}$.

Since hydrogels are beneficial for wound healing and represent excellent platforms for delivery of actives, the high number of reports on hydrogels impregnated with silver is not surprising ${ }^{67,93}$. With constantly arising novel silverbased dressing types in terms of design, a handful of silver- 
impregnated hydrogels are already at the market. Some examples include the AQUACEL ${ }^{\circledR} \mathrm{Ag}$ from ConvaTec - a physically cross-linked carboxymethyl cellulose hydrogel reinforced by a non-woven fabric based on their Hydrofiber ${ }^{\circledR}$ technology, and the Acticoat ${ }^{\mathrm{TM}}$ Absorbent from Smith \& Nephew - a two-layer dressing composed of silver-coated polyethylene bonded to an absorbent rayon/polyester core (silver is released continuously during 3 days upon humidification), whereas the SilvaSorb ${ }^{\circledR}$ is silver-containing amorphous gelling hydrogel from Medline still requires secondary dressing for its application.

Although bacterial resistance to silver is less likely to occur as opposed to antibiotics ${ }^{94}$, it is still essential the application of silver in amounts that do not exert adverse health effects. To this end, silver is as well processed into nanomaterial structures with similar to the ionic silver antimicrobial potential, however, at far lower concentrations 95. Nucryst Pharmaceuticals is one of the first companies to apply nanosized silver particles into clinically proven medical products that fight infection and inflammation using. Nucryst's manufacturing technology is based on a physical vapour deposition (PVD) process called magnetron sputtering. Advanced wound dressings with this technology are sold by Smith \& Nephew as Acticoat ${ }^{\mathrm{TM}}$ used in the treatment of different wounds or burns. The natural antibiotic properties of nanocrystalline silver become more pronounced as the particles become smaller and can react more readily with the body.

Other natural-based antimicrobial compounds, such as plant polyphenols, could also be added to polymer mixtures prior to chemical cross-linking, and eventually released in a sustained manner from such platforms ${ }^{77,96}$. Since these compounds are relatively unstable in physiological conditions, their encapsulation for protection into polymer nano-/micro-carriers to improve their hydrolytic resistance and their potential to inhibit bacteria growth and deleterious chronic wound enzymes is necessary. This area of investigation is still in its outset, but holds a great potential since nano-/micro-processed polyphenols are themselves active, while simultaneously can be employed as carriers for delivery of other active compounds. In one such approach, the green tea polyphenol epigallocatechin gallate (EGCG) was sonochemically processed into nanospheres and further incorporated into a chitosan-based hydrogel via enzymemediated gelation, using peroxidases ${ }^{81}$. Importantly, the nanospheres integrity was not compromised during the gelation process, maintaining their chronic wound healing capacity via enhanced antibacterial and chronicity factors inhibition compared to the EGCG free solution. These nanospheres were released from the hybrid hydrogel in a sustained manner over 6 days, in compliance with the clinical practice requirement for prolonged usage and low frequency of wound dressing change ${ }^{97}$. Another technological approach recently patented under US8912247 B2 presented a hydrogel-based porous construct comprising a biodegradable poly(propylene fumarate) and protein microparticles entrapping both a biologically active substance and a free-radical initiator promoting the gel crosslinking. These super-absorbent hydrogel microparticles swell considerably, but still maintain a defined shape due to the controlled cross-linking. The cross-linked dressing is easily applicable to human tissues and provides sustained release of active compounds ${ }^{98}$.

\subsubsection{Stimuli-responsive hydrogels}

The release of active agents from a hydrogel may follow several mechanisms and can be controlled by diffusion, swelling, chemical reactions and/or environmental stimuli. Stimuli-responsive hydrogels allow for high levels of control over release in response to known external cues. Such enhanced control has enabled advances in healthcare and more effective therapies, including improved wound healing 99. Diverse responsive modalities are being investigated, however, their entry into clinical trials is usually restricted mostly because of targeting limitations. Temperature-, $\mathrm{pH}-$ and enzyme-responsive hydrogels are the most interesting materials for wound treatments.

Alteration of the $\mathrm{pH}$ in inflamed tissue/wounds may trigger the degradation and release of active compounds from $\mathrm{pH}$-responsive hydrogels. The triggering principle is based on swelling/deswelling imparted by the presence of ionisable functional groups in the gel polymer, following the rationale that anionic networks swell at $\mathrm{pH}>\mathrm{pKa}$ and cationic at $\mathrm{pH}<\mathrm{pKa}{ }^{100}$. Whereas monomers such as acrylates and acrylamide are exploited to induce $\mathrm{pH}$ responsiveness in synthetic polymers, natural polymers may also be intrinsically responsive. Such examples are proteins that deswell due to their helical structure near the isoelectric point and swell at changing $\mathrm{pH}$. In certain polysaccharides (e.g. chitosan, alginate) physical crosslinking can be achieved by grafting D-/L-lactic acid and/or glycolic acid via the hydrophobic side chains aggregation and intermolecular interactions through hydrogen bonds between side and main polymer chains. After stabilisation by hydrophobic interactions, the swelling occurs upon the ionization of their functional groups to induce build-up of charge and subsequent electrostatic repulsion ${ }^{101}$.

Temperature-responsive hydrogels for medical use responding to physiological temperature $\left(37^{\circ} \mathrm{C}\right)$ are the subject of intense investigation for the development of a number of mechanisms to manipulate and control temperature in vivo. Two main categories exist - positively and negatively responsive hydrogels with upper critical solution temperature (UCST) and lower critical solution temperature (LCST), respectively. Their collapse /expansion occurs with the critical shift in aqueous solubility used for delivery of actives and even in situ gelation ${ }^{102}$. Especially the polymers that exhibit LCSTs close to physiological temperature are preferred for biomedical purposes. For instance, hydrogels composed of poly(Nisopropylacrylamide) (PNIPAAm) and its copolymers have LCST $\sim 32{ }^{\circ} \mathrm{C}$ that can be easily modified by a number of monomers ${ }^{103}$. Polyethylene glycol (PEG) is another biomedical amphiphilic polymer that provides "stealthing" of unstable drugs while demonstrating negative temperature response in physiological environment in combination with 
suitable comonomers ${ }^{104}$. As temperature increases the swelling of the PEG-methacrylate hydrogels decrease. The responsiveness can be further tuned by changing the Mw of the PEG component.

Copolymer hydrogels are useful for compensation of a limited delivery, frequently faced in case of platforms responding to only one stimulus. Besides the protection of unstable drugs, functional copolymers respond to a set of stimuli and different environmental conditions (light, temperature, $\mathrm{pH}$, ionic strength, electric field, shear stress, etc.) ${ }^{105}$. One such material used for preparation of dualresponsive hydrogels is poly( $\mathrm{N}$-isopropylacrylamide-coacrylic acid) (poly(NIPAAm-co-AAc)), a copolymer usually synthesised via radical copolymerization of $\mathrm{N}$ isopropylacrylamide (NIPAAm) and acrylic acid merging both temperature- and $\mathrm{pH}$-sensitive coil to globule phase transition. Tuning the amount of acrylic acid added to the copolymer structure serves for controlling its LCST ${ }^{106}$. Whereas its thermosensitivity brings about in situ gelation properties exploited for wound dressings, subsequent $\mathrm{pH}$ reasponsiveness within the biological $\mathrm{pH}$ range ensures the delivery of actives. Poly(NIPAAm-co-AAc) has been indicated as appropriate for delivery of proteins, i.e. vascular endothelial growth factor (VEGF) and epidermal growth factor (EGF), within the range of wound $\mathrm{pH}$ 6.7-7.9 ${ }^{107}$. Yet another dual stimuli-responsive ( $\mathrm{pH}$ and temperature) material is poly(amidoamine) oligomer hydrogel indicated as reliable carrier of active compounds since its unique structure avoids their burst release ${ }^{108}$.

Enzyme-responsive hydrogels are new materials which can undergo changes in their microscopic properties upon the activity of physiological enzymes. Such materials have high potential for management and treatment of wounds as variety of proteolytic enzymes are found in the wound bed. Hydrogels responsive to protease degradation can be loaded with different wound healing promoters, such as growth factors or cytokines, to design enzyme-triggered delivery systems providing an alternative approach to regulating the bioavailability of therapeutic agents to the wound site. For their fabrication, usually proteins are used, such as collagen and elastin that undergo proteolytic degradation when triggered by the complex of matrix metalloproteinases MMPs ${ }^{109}$. On the other hand, MMPs-sensitive hydrogels for tissue repair were also developed by crosslinking linear peptide substrates for MMPs into 3D scaffolds on reaction with end-functionalized PEG macromers (Figure 1) 110,111. The integration of protease sensitive peptides into the hydrogel matrix to fine-tune its degradation was demonstrated during the screening of 17 protease substrates for their degradability upon the activity of the MMP-1 and MMP-2 in soluble form and in the context of biodegradable cross-linkers within molecularly engineered PEG hydrogels. The latter could be employed to engineer hydrogels with specific degradation properties depending on the targeted cell types. The presence of peptides had resulted in faster degradation of the hydrogels when exposed to the appropriate MMPs and had led to increased cell spreading and cell invasion ${ }^{111}$.

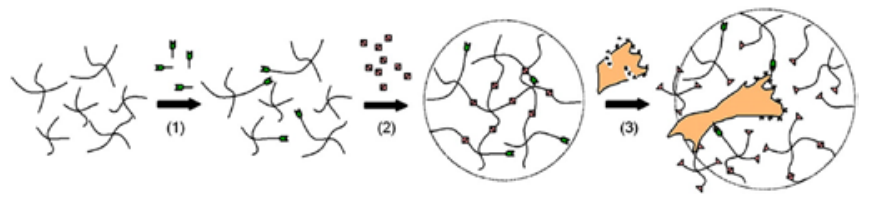

Figure 1. A Michael-type addition reaction between vinyl sulfone-functionalised multiarm PEG and mono-cysteine adhesion peptides (step 1) or bis-cysteine MMP substrate peptides (step 2). The hydrogels were formed from aqueous solutions in the presence of cells and respond to local protease activity at the cell surface (step 3) ${ }^{110}$. Copyright (2003) National Academy of Sciences

Whenever synthetic hydrogels scaffolds are being developed, the presence of integrin-binding sites and enzyme specific degradation sites is required in order to ensure the hydrogel degradability. In fibrin, the degree of proteolytic degradation and the controlled release of growth factors could be partially modulated by crosslinking with engineered protein (aprotinin) fragments to tailor its properties towards specific applications ${ }^{112}$. Also, a multifunctional recombinant fragment of fibronectin comprising integrin-binding domains and skin and bone growth factors was engineered to promote wound and bone tissue healing. The developed material greatly enhanced the regenerative effects of the growth factors in vivo in a diabetic mouse model of chronic wounds and in a rat model of critical-size bone defects ${ }^{113}$.

\subsection{Hydrogel dressings for sensor and imaging of wound healing}

The wound diagnosis follows a series of standard steps including physical examination and imaging of the wound to establish the wound aetiology and the current status. The whole procedure is often quite lengthy since it also involves cleaning and/or debridement of the wound and swabbing for detection of infection. Only the latter step requires costly ex vivo analyses, special equipment and laboratory tests that take days to complete. The cumulative delays postpone the application of appropriate treatment making more difficult the successful management and lead to increased cost. Thus, rapid accurate assessments completed at the bedside or during a medical consultation are needed.

A relatively new concept of point-of-care (POC) technologies is designed to provide fast, accurate and inexpensive medical assessments at the bedside ${ }^{114}$. In wounds, POC assessment is expected to ensure effective diagnosis based on specific biomarkers or less specific evaluation of wound-related parameters (margin, volume, depth and area). Since all wounds are different and respond differently to the specific treatment, a simple, but accurate diagnosis would avoid a variety of expensive procedures during which the diagnosis persists wrong.

For these reasons, biological or chemical sensors of wound exudates and volatiles to directly or indirectly detect bacteria, wound $\mathrm{pH}$, temperature, oxidative stress and enzymes are rapidly paving their way for advanced wound screening in clinical settings. From a material point of view, the biggest challenge is the integration of such sensors into a dressing without losing their sensing properties. Hydrogels offer an advantage over other wound dressing materials for 
wound monitoring, because they easily entrap active molecules minimally affecting their biological properties. Yet another advantage of hydrogels is their transparency, as wound closure can be constantly monitored without removing the dressing. Hydrogels are thus being intensively studied as carriers of sensing modalities for screening of the wound status.

\subsubsection{Temperature as a parameter for wound diagnosis}

During the healing process different parameters in wounds alter continuously. Heat is an established marker of wound infection or non-healing state, used as a relatively reliable early predictor of chronicity before any visual changes in the appearance of the wound are obvious ${ }^{115}$. To avoid painful measuring of wound temperature with handheld thermometers, temperature sensors are incorporated into wound dressings.

For instance, wireless temperature sensors based on thermo-resistivity of carbon nanotubes can predict initiation of pressure ulcers and upcoming inflammation ${ }^{116}$. The laboratory research showed a great promise and these sensors were further tested on healthy volunteers. However, no advances have been made since to test them on patients at risk to develop bed sores. Approaches also exist to avoid the use of wireless technology, incorporating in the wound dressing indicators of temperature, such as colorimetric sensors for measuring heat. Different colorimetric sensors have been tested for wound management including those based on stimuli-responsive polymers attached to porous silicon (pSi) - a popular substrate for optical biosensor manufacturing - in order to design temperature and also $\mathrm{pH}$ sensors ${ }^{117-119}$. Like that, a stimulus-responsive inorganicorganic composite has been prepared via surface-initiated atom transfer radical polymerisation thus grafting a thermoresponsive PNIPAAm to pSi films ${ }^{120}$. Its optical properties changed noticeably with temperature and are reversible around the LCST of the PNIPAM component. Such sensors are expected to be soon incorporated into hydrogel dressings and tested in wound environments.

\subsection{2. $\mathrm{pH}$ as a parameter for wound diagnosis}

During the course of wound healing $\mathrm{pH}$ changes in response to biochemical alterations. The common range of $\mathrm{pH}$ from 4 to 6 of healthy epidermis significantly rises upon tissue damage and induction of the immune defence. Such changes are in the base of a conventional method to increase the healing rate in chronic venous leg ulcers inducing prolonged chemical acidification of the wound ${ }^{121}$. Different $\mathrm{pH}$ values across distinct phases of the wound healing process ${ }^{122}$ render $\mathrm{pH}$ a powerful parameter for wound monitoring while available technologies may lead to the building of advanced dressing platforms.

In line with this, a microfabricated wireless $\mathrm{pH}$ monitoring transducer that sandwich a poly(vinylalcohol)poly(acrylicacid) hydrogel was developed for continuous tracking of $\mathrm{pH}$. Since the hydrogel is $\mathrm{pH}$-responsive it swells/deswells with $\mathrm{pH}$ changing the distance separating the transducer which in turn results in a linear change of inductance over the $\mathrm{pH}$ range 2-7 ${ }^{123}$. Also, the wireless measurement of the coil gap (and thus $\mathrm{pH}$ ) is possible by using antenna, allowing coverage of the hydrogel by a secondary security bandage - approach commonly used in wound management for application and removal of dressings.

Another approach employs time-domain luminescence sensing of biological parameters for a visual detection of the $2 \mathrm{D} \mathrm{pH}$ distribution in wounds ${ }^{124}$. Here the sensing scheme is based on two different luminescence dyes bound on polymeric microparticles further immobilised in biocompatible polyurethane transparent hydrogel. Different luminescence life times of the two dyes make possible the detection of differences in the signals during the excitation and emission phases related to the $\mathrm{pH}$ dependency of one of them. The sensor precision was validated in vitro and in vivo during cutaneous chronic wound healing in humans (Figure 2), rendering it a promising approach to pattern a wound map.
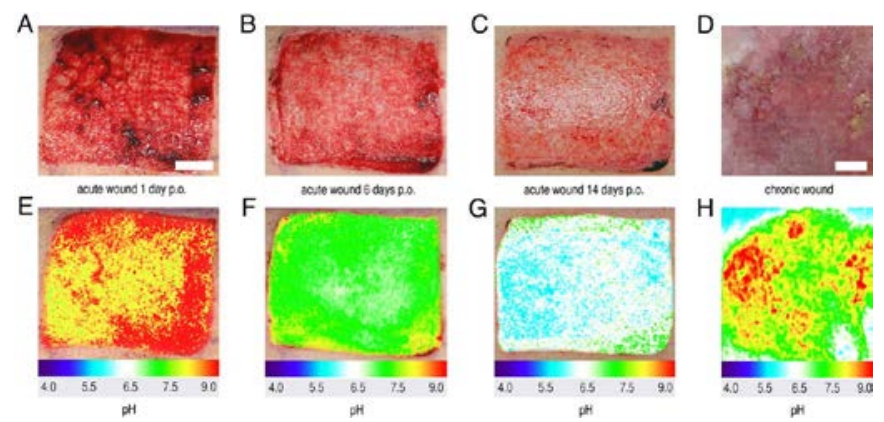

Figure 2. Luminescence imaging of $\mathrm{pH}$ during cutaneous wound healing. (A, B, C) Wound healing of $\sim 400 \mu \mathrm{m}$ skingraft donor sites during (A) inflammation), (B) granulation, and (C) reepithelialisation. (E, F, G) Respective images created with optical 2D pH sensors, where healing is observed by decreased $\mathrm{pH}$. (D, H) Chronic venous ulcer (D) on the medial ankle and the respective $\mathrm{pH}$ distribution $(\mathrm{H})$. The colours allow a correlation with the wound-healing phases, demonstrated for physiological healing (E, F, G). Scale bars are $1 \mathrm{~cm}^{124}$. Copyright (2011) National Academy of Sciences

Recently, a flexible pH-responsive fibrous hydrogel is suggested for long-term monitoring of wound condition ${ }^{125}$. The hydrogel fibres were fabricated using an easily scalable microfluidic spinning system. Mesoporous microparticles bearing $\mathrm{pH}$-responsive dyes are embedded in the fibres. Images during real-time $\mathrm{pH}$ measurement are captured with a smart phone camera allowing bedside readout. Via image processing, a quantitative $\mathrm{pH}$ map of the wound bed can be extracted to predict the wound healing process.

\subsubsection{Infection biomarkers}


Possibly the most common cause of preventing wounds from healing is their bacterial colonisation and subsequently infection. Infection per se is easily recognisable with signs such as redness, heat, swelling, odour, exudate, pain in patient, bleeding on contact, tissue breakdown and epithelial bridging ${ }^{126}$. However, the challenge in wound management is to detect infection before it reaches advanced stages, while the lack of rapid and reliable detection methods are compromising this task.

What appears as one reliable solution is the detection of different enzyme biomarkers secreted by the immune system, based on their reaction with specific substrates resulting in colour change. Inflammation precedes the infection process and due to the innate immune response, neutrophils are present in the wound site before the infection bursts. Elevated levels of almost all neutrophil-derived enzymes leads to new perspectives in screening of infection status ${ }^{127-129}$. The expected response of enzyme-based assays based on changing enzyme activity levels is rapid, simple (infected or non-infected) and may be detectable by naked eye (colour generation). Though the colour response does not provide information about the involved bacteria species, an indication of any early infection may drastically change the outcomes in the wound management. Readers are referred to excellent articles with extended registers for details on monitoring wound status based on enzyme activities related to infections ${ }^{130,131}$. Instead, this short review explains only the basic principles of these detection concepts and their integration in hydrogel-based dressings.

The major advances in the enzyme-based wound screening are achieved for detection of proteases, since these enzymes are typically found in elevated levels in non-healing wounds. A POC test material for protease status, WOUNDCHECK ${ }^{\mathrm{TM}}$ from Systagenix, detects elevated total protease activity to assess whether neutrophil associated proteases are present in the wound or not ${ }^{132}$, since a whole group of proteolytic MMP enzymes, such as gelatinases and collagenases characterise most of the chronic and/or infected wounds. On the other hand, a more specific method for detecting only gelatinases, such as MMP-2 and MMP-9 in wounds, employs sensors based on pSi films, spin-coated with the gelatine substrate ${ }^{133}$. The gelatine cleavage results in the entrance of its hydrolysis products into the pSi pores where a colour change could be observed. The inconvenience of this diagnostic system is that any liquid diffusing into the pores would trigger the colour change. The authors thus further propose an additional step of drying the material and adding glycerol after the reaction to confirm the enzymatic cleavage.

Human neutrophil elastase (HNE) is another proteolytic enzyme common in chronic wounds, which activity was detected by the use of dextran hydrogel films chemically functionalised via imine linkages with the specific peptide substrate for HNE (Ala-Ala-Pro-Val-Ala-Ala-Lys) and further coated on a quartz crystal ${ }^{134}$. Upon degradation of the hydrogel film, a change in resonance frequency was detected by the quartz crystal microbalance (QCM) measurements. The hydrogel degradation rate, controlled by the gel cross-link density, was correlated with the HNE activity. Though such device offers quantification of the specific inflammatory markers, the use of sophisticated analytical techniques such as QCM is not considered a simple diagnostic method suitable for clinical practice. Thus, visual perception of wound infection/inflammation status is preferable.

Wound fluids with persistent inflammation that precedes infections indeed contain significantly increased enzymatic activities that can be conveniently measured using specific substrates, such as N-methoxysuccinyl-Ala-Ala-Pro-Val pnitroanilide for HNE. Sensor materials containing these substrates should be optimised to detect enzymatic activities in the window between normal healing and infected wounds. Upon elastase cleavage, p-nitroanilide chromophore is released from the platform resulting in colour formation and detection of infection in early stage. Different materials including collagen films, and transparent matrices of hyaluronic acid were used as carriers of aminated silica gels on which the substrate are covalently immobilised via carbodiimide chemistry ${ }^{135}$. Chromophore release and thus colour formation was observed only in the case of incubation of these materials with infected wound fluids confirming their potential for diagnostic application. Similarly to HNE, the activity of cathepsin $G$ (CatG) was found to be significantly elevated in infected wounds. The activity of CatG could be detected upon the same principles as for HNE, using its specific substrate N-Succinyl-Ala-Ala-ProPhe p-nitroanilide NSuc-AAPF-pNA. Substrates for CatG were also immobilised on aminated silica gels that were further incorporated in the same materials. A colour change was also visible only upon incubation with infected wound fluids ${ }^{135}$. Other useful enzyme for detection is $\beta$ glucuronidase secreted by commonly found in infected wounds Escherichia coli strains. Its chromogenic and fluorogenic substrates, respectively 4-nitrophenyl- $\beta$-Dglucuronide and 4-methylumbelliferyl- $\beta$-D-glucuronide can be covalently attached to chitosan-based hydrogel to produce self-reporting material sensitive to small quantities of bacteria presence. Rapid cleavage of dyes (within minutes) produces a stable signal for the bacteria presence, detectable by bare eye or under appropriate illumination ${ }^{136}$. This simple bacteria detection approach (Figure 3) is suggested as

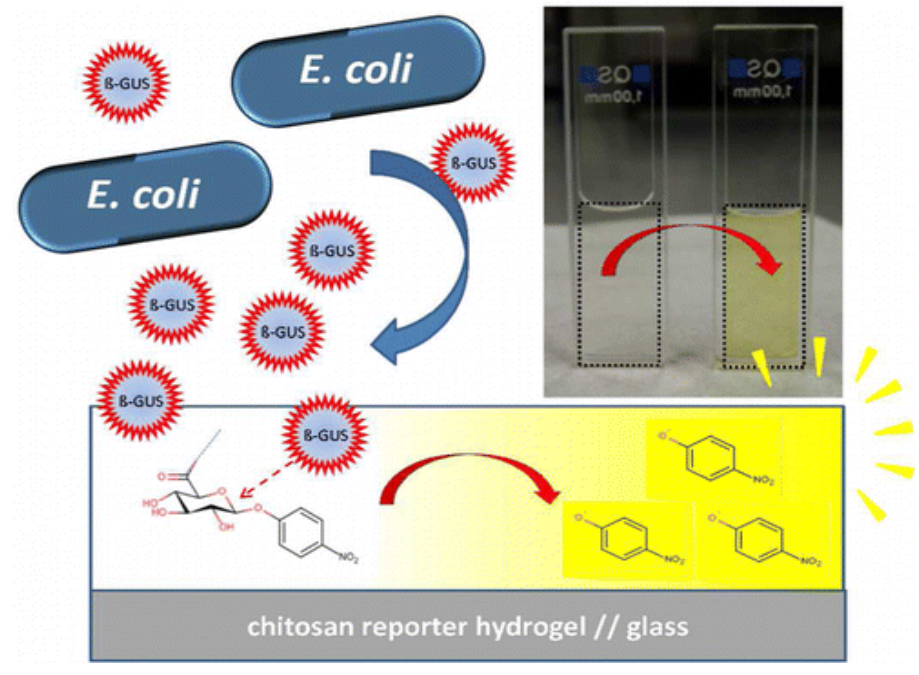


amenable for both wound dressings and packaging materials.

Figure 3. The concept and photograph of sensing Escherichia coli based on 4-nitrophenyl- $\beta$-D-glucuronide grafted onto chitosan hydrogel before and after completing the reaction with $\beta$-glucuronidase ( $\beta$-GUS) released by bacteria (within 15 minutes). Reproduced with permission ${ }^{136}$. Copyright (2015) American Chemical Society

As for other inflammation-related diseases, significantly altered lysozyme (Lys) activity is also tightly connected with wounds colonised with bacteria ${ }^{137,138}$. Lys is a glycosidase that hydrolyses the glycosidic linkages of peptidoglycans in bacterial cell walls, to which it owes its antibacterial potential. Thus, materials fabricated from peptidoglycans are capable to detect elevated lysozyme activities in wound fluids based on their direct hydrolysis. To this end, hydrogels comprising agarose and peptidoglycan components were fabricated for visual detection approach and degraded in presence of Lys ${ }^{137}$. The enzymatic activity is linear to the change in turbidity of the remaining solution. Since such measurement was not sufficiently sensitive, the peptidoglycan component was further stained with Remazol Brilliant Blue dye to enable a photometrical detection. However, a clear visual perception of infection upon colour change could be only observed after enhancing the detection signal. To do so, the agarose and peptidoglycan layers were modified by covalently attaching polyphenol ferulic acid onto the former and polyethylene glycol-modified laccase onto the latter ${ }^{139}$. The digestion of peptidoglycan by lysozyme led to the release of laccase that oxidised polyphenols and resulted in clearly visible colour changes.

\section{CONCLUSION}

Hydrogels are already widely present at the market as the most comfortable dressings that provide moisture environment beneficial for wound healing and absorb excess exudate. Nonetheless, their true potential is yet to be explored and lies in the possibility for combining them with active molecules that accelerate or allow for screening of the healing process. During the last decade a significant amount of data has emerged with regards to the use of hydrogels as platforms in advanced dressings for enhanced skin regeneration. Mastering the fabrication processes and reasonable control of the properties of the novel multifunctional dressings are now achievable. The greatest progress has been realised in the design of smart hydrogels for stimuli-responsive drug delivery and/or monitoring the wound status. Attempts are currently being made to increase the efficiency and lower the price of the designed dressings in order to reach the market. Indeed, the lack of advanced commercial products with hydrogels in drug delivery and wound screening is related to their high production costs and policies of the companies to look for less expensive and simpler solutions. Engaging multiple activities in a single dressing means also a more complex validation and regulatory procedures. Additionally, clinical investigations are as well essential before smart hydrogels can be routinely adopted as platforms for delivery of pharmacological agents in clinical practice.

\section{ACKNOWLEDGEMENTS}

Antonio Francesko, PhD: Responsible for the bibliography collection and review writing. First author and co-author of several articles related to development of smart hydrogels cited in this review.

Petya Petkova, PhD: She participated in the writing and technical editing of the review. She is also the first author of one article cited in this review related to development of smart hydrogels with incorporated nanoparticle systems.

Tzanko Tzanov, PhD (corresponding author): Coordinator of the Group of Molecular and Industrial Biotechnology. Principal investigator and supervisor of all works related with the development of smart hydrogels carried out in the group. He also participated in the writing and technical editing of the review.

\section{REFERENCES}

\section{Journal Reference:}

[1] Rowan, M. P.; Cancio, L. C.; Elster, E. a; Burmeister, D. M.; Rose, L. F.; Natesan, S.; Chan, R. K.; Christy, R. J.; Chung, K. K. Burn Wound Healing and Treatment: Review and Advancements. Crit. Care 2015, 19 (1), 243.

[2] Werdin, F.; Tennenhaus, M.; Schaller, H.-E.; Rennekampff, H.-O. Evidence-Based Management Strategies for Treatment of Chronic Wounds. Eplasty 2009, 9, e19.

[3] Church, D.; Elsayed, S.; Reid, O.; Winston, B.; Lindsay, R. Burn Wound Infections. Clin. Microbiol. Rev. 2006, 19 [2], 403-434.

[4] Vermonden, T.; Censi, R.; Hennink, W. E. Hydrogels for Protein Delivery. Chem. Rev. 2012, 112 (5), 2853-2888.

[5] Prabaharan, M.; Mano, J. F. Stimuli-Responsive Hydrogels Based on Polysaccharides Incorporated with Thermo-Responsive Polymers as Novel Biomaterials. Macromol. Biosci. 2006, 6 (12), 991-1008.

[6] Gupta, P.; Vermani, K.; Garg, S. Hydrogels: From Controlled Release to $\mathrm{pH}$-Responsive Drug Delivery. Drug Discov. Today 2002, 7 (10), 569-579.

[7] Koetting, M. C.; Peters, J. T.; Steichen, S. D.; Peppas, N. A. Stimulus-Responsive Hydrogels: Theory, Modern Advances, and Applications. Mater. Sci. Eng. R Reports 2015, 93, 1-49.

[8] Jones, V.; Grey, J. E.; Harding, K. G. Wound Dressings. BMJ 2006, 332 (7544), 777-780.

[9] Wichterle, O.; Lím, D. Hydrophilic Gels for Biological Use. Nature 1960, 185 (4706), 117-118.

[10] Ahmed, S.; Ikram, S. Chitosan Based Scaffolds and Their Applications in Wound Healing. Achiev. Life Sci. 2016, 10 (1), 27-37.

[11] Francesko, A.; Tzanov, T. Chitin, Chitosan and Derivatives for Wound Healing and Tissue Engineering. Adv. Biochem. Eng. Biotechnol. 2010.

[12] Cho, Y. W.; Cho, Y. N.; Chung, S. H.; Yoo, G.; Ko, S. W. WaterSoluble Chitin as a Wound Healing Accelerator. Biomaterials 1999, 20 (22), 2139-2145. 
[13] Uchio, Y.; Ochi, M.; Matsusaki, M.; Kurioka, H.; Katsube, K. Human Chondrocyte Proliferation and Matrix Synthesis Cultured in Atelocollagen ${ }^{\circledR}$ Gel. J. Biomed. Mater. Res. 2000, 50 (2), 138143.

[14] Parkhurst, M. R.; Saltzman, W. M. Quantification of Human Neutrophil Motility in Three-Dimensional Collagen Gels. Effect of Collagen Concentration. Biophys. J. 1992, 61 (2), 306-315.

[15] Saltzman, W. M.; Parkhurst, M. R.; Parsons-Wingerter, P.; Zhu, W. - H. Three- dimensional Cell Cultures Mimic Tissues. Ann. N. Y. Acad. Sci. 1992, 665 (1), 259-273.

[16] Francesko, A.; Fernandes, M. M.; Rocasalbas, G.; Gautier, S.; Tzanov, T. Polymers in Wound Repair BT - Advanced Polymers in Medicine. In; Puoci, F., Ed.; Springer International Publishing: Cham, 2015; pp 401-431.

[17] Mogoşanu, G. D.; Grumezescu, A. M. Natural and Synthetic Polymers for Wounds and Burns Dressing. Int. J. Pharm. 2014, 463 (2), 127-136.

[18] Grainger, D. W. Wound Healing: Enzymatically Crosslinked Scaffolds. Nat Mater 2015, 14 (7), 662-663.

[19] Raguvaran, R.; Manuja, B. K.; Chopra, M.; Thakur, R.; Anand, T.; Kalia, A.; Manuja, A. Sodium Alginate and Gum Acacia Hydrogels of ZnO Nanoparticles Show Wound Healing Effect on Fibroblast Cells. Int. J. Biol. Macromol. 2017, 96, 185-191.

[20] Balakrishnan, B.; Mohanty, M.; Fernandez, A. C.; Mohanan, P. V.; Jayakrishnan, A. Evaluation of the Effect of Incorporation of Dibutyryl Cyclic Adenosine Monophosphate in an in SituForming Hydrogel Wound Dressing Based on Oxidized Alginate and Gelatin. Biomaterials 2006, 27 (8), 1355-1361.

[21] Balakrishnan, B.; Mohanty, M.; Umashankar, P. R.; Jayakrishnan, A. Evaluation of an in Situ Forming Hydrogel Wound Dressing Based on Oxidized Alginate and Gelatin. Biomaterials 2005, 26 (32), 6335-6342.

[22] Guillem Rocasalbas Sonia Touriño, Xavier Fernández-Francos, Georg M Guebitz, Tzanko Tzanov, A. F. Laccase-Assisted Formation of Bioactive Chitosan/gelatin Hydrogel Stabilized with Plant Polyphenols. Carbohydr. Polym. 2013, 92 (2), 989-996.

[23] Wu, J.; Sailor, M. J. Chitosan Hydrogel-Capped Porous SiO2 as a $\mathrm{pH}$ Responsive Nano-Valve for Triggered Release of Insulin. Adv Funct. Mater. 2009, 19 (5), 733-741.

[24] Carvalho, I. C. Engineered 3D-Scaffolds of Photocrosslinked Chitosan-Gelatin Hydrogel Hybrids for Chronic Wound Dressings and Regeneration. Mater. Sci. Eng. C 2017, 78, 690-705.

[25] Hashmi, M. U.; Khan, F.; Khalid, N.; Shahid, A. A.; Javed, A.; Alam, T.; Jalal, N.; Hayat, M. Q.; Abbas, S. R.; Janjua, H. A. Hydrogels Incorporated with Silver Nanocolloids Prepared from Antioxidant Rich Aerva Javanica as Disruptive Agents against Burn Wound Infections. Colloids Surfaces A Physicochem. Eng. Asp. 2017, 529, 475-486.

[26] Bankoti, K.; Rameshbabu, A. P.; Datta, S.; Maity, P. P.; Goswami, P.; Datta, P.; Ghosh, S. K.; Mitra, A.; Dhara, S. Accelerated Healing of Full Thickness Dermal Wounds by Macroporous Waterborne Polyurethane-Chitosan Hydrogel Scaffolds. Mater. Sci. Eng. C 2017, 81, 133-143.

[27] Shukla, R.; Kashaw, S. K.; Jain, A. P.; Lodhi, S. Fabrication of Apigenin Loaded Gellan Gum-Chitosan Hydrogels (GGCH-HGs) for Effective Diabetic Wound Healing. Int. J. Biol. Macromol. 2016, 91, 1110-1119.

[28] Amin, M. A.; Abdel-Raheem, I. T. Accelerated Wound Healing and Anti-Inflammatory Effects of Physically Cross Linked Polyvinyl Alcohol-Chitosan Hydrogel Containing Honey Bee Venom in Diabetic Rats. Arch. Pharm. Res. 2014, 37 (8), 10161031.

[29] Miguel, S. P.; Ribeiro, M. P.; Brancal, H.; Coutinho, P.; Correia, I. J. Thermoresponsive Chitosan-Agarose Hydrogel for Skin Regeneration. Carbohydr. Polym. 2014, 111, 366-373.

[30] Yoon, D. S.; Lee, Y.; Ryu, H. A.; Jang, Y.; Lee, K. M.; Choi, Y.; Choi, W. J.; Lee, M.; Park, K. M.; Park, K. D.; et al. Cell Recruiting Chemokine-Loaded Sprayable Gelatin Hydrogel Dressings for Diabetic Wound Healing. Acta Biomater. 2016, 38, 59-68.

[31] Lee, Y.; Bae, J. W.; Lee, J. W.; Suh, W.; Park, K. D. EnzymeCatalyzed in Situ Forming Gelatin Hydrogels as Bioactive Wound
Dressings: Effects of Fibroblast Delivery on Wound Healing Efficacy. J. Mater. Chem. B 2014, 2 (44), 7712-7718.

[32] Sargeant, T. D.; Desai, A. P.; Banerjee, S.; Agawu, A.; Stopek, J. B. An in Situ Forming Collagen-PEG Hydrogel for Tissue Regeneration. Acta Biomater. 2012, 8 (1), 124-132.

[33] Helary, C.; Zarka, M.; Giraud-Guille, M. M. Fibroblasts within Concentrated Collagen Hydrogels Favour Chronic Skin Wound Healing. J. Tissue Eng. Regen. Med. 2012, 6 (3), 225-237.

[34] Jridi, M.; Bardaa, S.; Moalla, D.; Rebaii, T.; Souissi, N.; Sahnoun, Z.; Nasri, M. Microstructure, Rheological and Wound Healing Properties of Collagen-Based Gel from Cuttlefish Skin. Int. J. Biol. Macromol. 2015, 77, 369-374.

[35] Ribeiro, M. P.; Morgado, P. I.; Miguel, S. P.; Coutinho, P.; Correia, I. J. Dextran-Based Hydrogel Containing Chitosan Microparticles Loaded with Growth Factors to Be Used in Wound Healing. Mater. Sci. Eng. C 2013, 33 (5), 2958-2966.

[36] Basu, A.; Lindh, J.; Ålander, E.; Strømme, M.; Ferraz, N. On the Use of Ion-Crosslinked Nanocellulose Hydrogels for Wound Healing Solutions: Physicochemical Properties and ApplicationOriented Biocompatibility Studies. Carbohydr. Polym. 2017, 174, 299-308.

[37] Goh, M. C.; Hwang, Y.; Tae, G. Epidermal Growth Factor Loaded Heparin-Based Hydrogel Sheet for Skin Wound Healing. Carbohydr. Polym. 2016, 147, 251-260.

[38] Kirker, K. R.; Luo, Y.; Nielson, J. H.; Shelby, J.; Prestwich, G. D. Glycosaminoglycan Hydrogel Films as Bio-Interactive Dressings for Wound Healing. Biomaterials 2002, 23 (17), 3661-3671.

[39] Wang, Y.; Han, G.; Guo, B.; Huang, J. Hyaluronan Oligosaccharides Promote Diabetic Wound Healing by Increasing Angiogenesis. Pharmacol. Reports 2016, 68 (6), 1126-1132.

[40] Catanzano, O.; D’Esposito, V.; Acierno, S.; Ambrosio, M. R.; De Caro, C.; Avagliano, C.; Russo, P.; Russo, R.; Miro, A.; Ungaro, F.; et al. Alginate-hyaluronan Composite Hydrogels Accelerate Wound Healing Process. Carbohydr. Polym. 2015, 131, 407-414. [41] Lu, B.; Lu, F.; Zou, Y.; Liu, J.; Rong, B.; Li, Z.; Dai, F.; Wu, D.; Lan, G. In Situ Reduction of Silver Nanoparticles by Chitosan-LGlutamic Acid/hyaluronic Acid: Enhancing Antimicrobial and Wound-Healing Activity. Carbohydr. Polym. 2017, 173, 556-565.

[42] Annabi, N.; Rana, D.; Shirzaei Sani, E.; Portillo-Lara, R.; Gifford, J. L.; Fares, M. M.; Mithieux, S. M.; Weiss, A. S. Engineering a Sprayable and Elastic Hydrogel Adhesive with Antimicrobial Properties for Wound Healing. Biomaterials 2017, 139, 229-243. Bhumkar, D. R.; Pokharkar, V. B. Studies on Effect of pH on Cross-Linking of Chitosan with Sodium Tripolyphosphate: A Technical Note. AAPS PharmSciTech 2006, 7 (2), E138-E143.

[44] Yari, A.; Yeganeh, H.; Bakhshi, H. Synthesis and Evaluation of Novel Absorptive and Antibacterial Polyurethane Membranes as Wound Dressing. J. Mater. Sci. Mater. Med. 2012, 23 (9), 21872202.

[45] Song, A.; Rane, A. A.; Christman, K. L. Antibacterial and CellAdhesive Polypeptide and Poly[ethylene Glycol] Hydrogel as a Potential Scaffold for Wound Healing. Acta Biomater. 2012, 8 (1), 41-50.

[46] Mishra, S. K.; Mary, D. S.; Kannan, S. Copper Incorporated Microporous Chitosan-Polyethylene Glycol Hydrogels Loaded with Naproxen for Effective Drug Release and Anti-Infection Wound Dressing. Int. J. Biol. Macromol. 2017, 95, 928-937.

[47] Kim, J. O.; Park, J. K.; Kim, J. H.; Jin, S. G.; Yong, C. S.; Li, D. X.; Choi, J. Y.; Woo, J. S.; Yoo, B. K.; Lyoo, W. S.; et al. Development of Polyvinyl Alcohol-Sodium Alginate Gel-MatrixBased Wound Dressing System Containing Nitrofurazone. Int. J. Pharm. 2008, 359 (1-2), 79-86.

[48] Gupta, A.; Kumar, R.; Upadhyay, N. K.; Surekha, P.; Roy, P. K. Synthesis, Characterization and Efficacy of Chemically Crosslinked PVA Hydrogels for Dermal Wound Healing in Experimental Animals. J. Appl. Polym. Sci. 2009, 111 (3), 14001408.

[49] Vogt, P. M.; Hauser, J.; Robbach, O.; Bosse, B.; Fleischer, W.; Steinau, H. U.; Reimer, K. Polyvinyl Pyrrolidone-Iodine Liposome Hydrogel Improves Epithelialization by Combining Moisture and Antisepsis. A New Concept in Wound Therapy. Wound Repair Regen. 2001, 9 (2), 116-122. 
[50] Langer, S.; Botteck, N. M.; Bosse, B.; Reimer, K.; Vogt, P. M.; Steinau, H. U.; Mueller, S. Effect of Polyvinylpyrrolidone-Iodine Liposomal Hydrogel on Wound Microcirculation in SKH1-Hr Hairless Mice. Eur. Surg. Res. 2006, 38 [1], 27-34.

[51] Singh, B.; Sharma, S.; Dhiman, A. Design of Antibiotic Containing Hydrogel Wound Dressings: Biomedical Properties and Histological Study of Wound Healing. Int. J. Pharm. 2013, 457 (1), 82-91.

[52] Singh, B.; Dhiman, A. Design of Acacia Gum-Carbopol-CrossLinked-Polyvinylimidazole Hydrogel Wound Dressings for Antibiotic/Anesthetic Drug Delivery. Ind. Eng. Chem. Res. 2016, 55 (34), 9176-9188.

[53] Mobed-Miremadi, M.; Grandio, D.; Kunkel, J. Polystyrene-Based Wound Healing Systems. In Wound Healing Biomaterials; 2016; Vol. 2, pp 309-334.

[54] Garnier, C.; Axelos, M. A. V; Thibault, J.-F. Phase Diagrams of Pectin-Calcium Systems: Influence of $\mathrm{pH}$, Ionic Strength, and Temperature on the Gelation of Pectins with Different Degrees of Methylation. Carbohydr. Res. 1993, 240, 219-232.

[55] Renard, D.; Lefebvre, J. Gelation of Globular Proteins: Effect of $\mathrm{pH}$ and Ionic Strength on the Critical Concentration for Gel Formation. A Simple Model and Its Application to $\beta$ Lactoglobulin Heat-Induced Gelation. Int. J. Biol. Macromol. 1992, 14 (5), 287-291.

[56] Bae, K. H.; Wang, L.-S.; Kurisawa, M. Injectable Biodegradable Hydrogels: Progress and Challenges. J. Mater. Chem. B 2013, 1 (40), 5371-5388.

[57] Teodorescu, M.; Negru, I.; Stanescu, P. O.; Drăghici, C.; Lungu, A.; Sârbu, A. Thermogelation Properties of poly(NIsopropylacrylamide) - Block - Poly(ethylene Glycol) - Block poly(N-Isopropylacrylamide) Triblock Copolymer Aqueous Solutions. React. Funct. Polym. 2010, 70 (10), 790-797.

[58] Rosiak, J. M.; Ulański, P. Synthesis of Hydrogels by Irradiation of Polymers in Aqueous Solution. Radiat. Phys. Chem. 1999, 55 (2), 139-151.

[59] Mozalewska, W.; Czechowska-Biskup, R.; Olejnik, A. K.; Wach, R. A.; Ulański, P.; Rosiak, J. M. Chitosan-Containing Hydrogel Wound Dressings Prepared by Radiation Technique. Radiat. Phys. Chem. 2017, 134, 1-7.

[60] Molina, R.; Jovancic, P.; Vilchez, S.; Tzanov, T.; Solans, C. In Situ Chitosan Gelation Initiated by Atmospheric Plasma Treatment. Carbohydr. Polym. 2014, 103 (1), 472-479.

[61] Ekenseair, A. K.; Boere, K. W. M.; Tzouanas, S. N.; Vo, T. N.; Kasper, F. K.; Mikos, A. G. Structure-Property Evaluation of Thermally and Chemically Gelling Injectable Hydrogels for Tissue Engineering. Biomacromolecules 2012, 13 (9), 2821-2830.

[62] Annabi, N.; Tamayol, A.; Uquillas, J. A.; Akbari, M.; Bertassoni, L. E.; Cha, C.; Camci-Unal, G.; Dokmeci, M. R.; Peppas, N. A.; Khademhosseini, A. 25th Anniversary Article: Rational Design and Applications of Hydrogels in Regenerative Medicine. Adv. Mater. 2014, 26 (1), 85-124.

[63] Liliana S Moreira Teixeira Clemens A van Blitterswijk, Pieter J Dijkstra, Marcel Karperien, J. F. Enzyme-Catalyzed Crosslinkable Hydrogels: Emerging Strategies for Tissue Engineering. Biomaterials 2012, 33 (5), 1281-1290.

[64] Rocasalbas, G.; Francesko, A.; Touriño, S.; Fernández-Francos, X.; Guebitz, G. M.; Tzanov, T. Laccase-Assisted Formation of Bioactive Chitosan/gelatin Hydrogel Stabilized with Plant Polyphenols. Carbohydr. Polym. 2013, 92 (2), 989-996.

[65] Sakai, S.; Ashida, T.; Ogino, S.; Taya, M. Horseradish Peroxidase-Mediated Encapsulation of Mammalian Cells in Hydrogel Particles by Dropping. J. Microencapsul. 2014, 31 (1), 100-104.

[66] Li, J.; Li, X.; Ni, X.; Wang, X.; Li, H.; Leong, K. W. SelfAssembled Supramolecular Hydrogels Formed by Biodegradable PEO-PHB-PEO Triblock Copolymers and $\alpha$-Cyclodextrin for Controlled Drug Delivery. Biomaterials 2006, 27 (22), 41324140.

[67] Salomé Veiga, A.; Schneider, J. P. Antimicrobial Hydrogels for the Treatment of Infection. Pept. Sci. 2013, 100 (6), 637-644.

[68] Censi, R.; Di Martino, P.; Vermonden, T.; Hennink, W. E. Hydrogels for Protein Delivery in Tissue Engineering. J. Control.
Release 2012, 161 (2), 680-692.

[69] Dargaville, T. R.; Farrugia, B. L.; Broadbent, J. A.; Pace, S.; Upton, Z.; Voelcker, N. H. Sensors and Imaging for Wound Healing: A Review. Biosens. Bioelectron. 2013, 41, 30-42.

[70] Hoare, T. R.; Kohane, D. S. Hydrogels in Drug Delivery: Progress and Challenges. Polymer (Guildf). 2008, 49 (8), 1993-2007.

[71] Drury, J. L.; Mooney, D. J. Hydrogels for Tissue Engineering: Scaffold Design Variables and Applications. Biomaterials 2003, 24 (24), 4337-4351.

[72] Vu, L. T.; Jain, G.; Veres, B. D.; Rajagopalan, P. Cell Migration on Planar and Three-Dimensional Matrices: A Hydrogel-Based Perspective. Tissue Eng. Part B. Rev. 2015, 21 (1), 67-74.

[73] Lin, H.-Y.; Peng, C.-W.; Wu, W.-W. Fibrous Hydrogel Scaffolds with Cells Embedded in the Fibers as a Potential Tissue Scaffold for Skin Repair. J. Mater. Sci. Mater. Med. 2014, 25 (1), 259-269. Shepherd, J.; Sarker, P.; Rimmer, S.; Swanson, L.; MacNeil, S.; Douglas, I. Hyperbranched poly[NIPAM] Polymers Modified with Antibiotics for the Reduction of Bacterial Burden in Infected Human Tissue Engineered Skin. Biomaterials 2011, 32 (1), 258267.

[75] Tian, J.; Wong, K. K. Y.; Ho, C.-M.; Lok, C.-N.; Yu, W.-Y.; Che, C.-M.; Chiu, J.-F.; Tam, P. K. H. Topical Delivery of Silver Nanoparticles Promotes Wound Healing. ChemMedChem 2007, 2 (1), 129-136.

[76] Puolakkainen, P. A.; Twardzik, D. R.; Ranchalis, J. E.; Pankey, S. C.; Reed, M. J.; Gombotz, W. R. The Enhancement in Wound Healing by Transforming Growth Factor- $\beta 1$ (TGF- $\beta 1$ ) Depends on the Topical Delivery System. J. Surg. Res. 1995, 58 (3), 321329.

[77] Francesko, A.; Soares da Costa, D.; Reis, R. L.; Pashkuleva, I.; Tzanov, T. Functional Biopolymer-Based Matrices for Modulation of Chronic Wound Enzyme Activities. Acta Biomater. 2013, 9 (2), 5216-5225.

[78] Sun, G.; Zhang, X.; Shen, Y.-I.; Sebastian, R.; Dickinson, L. E.; Fox-Talbot, K.; Reinblatt, M.; Steenbergen, C.; Harmon, J. W.; Gerecht, S. Dextran Hydrogel Scaffolds Enhance Angiogenic Responses and Promote Complete Skin Regeneration during Burn Wound Healing. Proc. Natl. Acad. Sci. 2011, 108 (52), 2097620981.

[79] Tavakoli, J.; Tang, Y. Honey/PVA Hybrid Wound Dressings with Controlled Release of antibioticsStructural, Physico-Mechanical and in-Vitro Biomedical Studies. Mater. Sci. Eng. C 2017, 77, 318-325.

[80] Stefanov, I.; Pérez-Rafael, S.; Hoyo, J.; Cailloux, J.; Santana Pérez, O. O.; Hinojosa-Caballero, D.; Tzanov, T. Multifunctional Enzymatically Generated Hydrogels for Chronic Wound Application. Biomacromolecules 2017, 18 (5), 1544-1555.

[81] Petkova, P.; Francesko, A.; Tzanov, T. Enzyme-Assisted Formation of Hybrid Biopolymer Hydrogels Incorporating Active Phenolic Nanospheres. Eng. Life Sci. 2015, 15 (4), 416-424.

[82] Felgueiras, H. P.; Amorim, M. T. P. Functionalization of Electrospun Polymeric Wound Dressings with Antimicrobial Peptides. Colloids and Surfaces B: Biointerfaces, 2017, 156, 133148.

[83] Paladini, F.; Meikle, S. T.; Cooper, I. R.; Lacey, J.; Perugini, V.; Santin, M. Silver-Doped Self-Assembling Di-Phenylalanine Hydrogels as Wound Dressing Biomaterials. J. Mater. Sci. Mater. Med. 2013, 24 (10), 2461-2472.

[84] Boonkaew, B.; Barber, P. M.; Rengpipat, S.; Supaphol, P.; Kempf, M.; He, J.; John, V. T.; Cuttle, L. Development and Characterization of a Novel, Antimicrobial, Sterile Hydrogel Dressing for Burn Wounds: Single-Step Production with Gamma Irradiation Creates Silver Nanoparticles and Radical Polymerization. J. Pharm. Sci. 2014, 103 (10), 3244-3253.

[85] Pallavicini, P.; Arciola, C. R.; Bertoglio, F.; Curtosi, S.; Dacarro, G.; D’Agostino, A.; Ferrari, F.; Merli, D.; Milanese, C.; Rossi, S.; et al. Silver Nanoparticles Synthesized and Coated with Pectin: An Ideal Compromise for Anti-Bacterial and Anti-Biofilm Action Combined with Wound-Healing Properties. J. Colloid Interface Sci. 2017, 498, 271-281.

[86] Yang, D. H.; Seo, D. I.; Lee, D. W.; Bhang, S. H.; Park, K.; Jang, G.; Kim, C. H.; Chun, H. J. Preparation and Evaluation of Visible- 
Light Cured Glycol Chitosan Hydrogel Dressing Containing Dual Growth Factors for Accelerated Wound Healing. J. Ind. Eng. Chem. 2017, 53, 360-370.

[87] Obara, K.; Ishihara, M.; Ishizuka, T.; Fujita, M.; Ozeki, Y.; Maehara, T.; Saito, Y.; Yura, H.; Matsui, T.; Hattori, H.; et al. Photocrosslinkable Chitosan Hydrogel Containing Fibroblast Growth Factor-2 Stimulates Wound Healing in Healing-Impaired Db/db Mice. Biomaterials 2003, 24 (20), 3437-3444.

[88] Liu, Y.; Cai, S.; Shu, X. Z.; Shelby, J.; Prestwich, G. D. Release of Basic Fibroblast Growth Factor from a Crosslinked Glycosaminoglycan Hydrogel Promotes Wound Healing. Wound Repair Regen. 2007, 15 (2), 245-251.

[89] Kaisang, L.; Siyu, W.; Lijun, F.; Daoyan, P.; Xian, C. J.; Jie, S. Adipose-Derived Stem Cells Seeded in Pluronic F-127 Hydrogel Promotes Diabetic Wound Healing. J. Surg. Res. 2017, 7, 1-12.

[90] Jones, S. A.; Bowler, P. G.; Walker, M.; Parsons, D. Controlling Wound Bioburden with a Novel Silver-Containing Hydrofiber ${ }^{\circledR}$ Dressing. Wound Repair Regen. 2004, 12 (3), 288-294.

[91] Bowler, P. G.; Jones, S. A.; Walker, M.; Parsons, D. Microbicidal Properties of a Silver-Containing Hydrofiber ${ }^{\circledR}$ Dressing Against a Variety of Burn Wound Pathogens. J. Burn Care Res. 2004, 25 (2), 192-196.

[92] Leaper, D. J. Silver Dressings: Their Role in Wound Management. Int. Wound J. 2006, 3 (4), 282-294.

[93] Finnegan, S.; Percival, S. L. Clinical and Antibiofilm Efficacy of Antimicrobial Hydrogels. Adv. Wound Care 2015, 4 (7), 398-406.

[94] Percival, S. L.; Bowler, P. G.; Russell, D. Bacterial Resistance to Silver in Wound Care. J. Hosp. Infect. 2005, 60 (1), 1-7.

[95] Wilkinson, L. J.; White, R. J.; Chipman, J. K. Silver and Nanoparticles of Silver in Wound Dressings: A Review of Efficacy and Safety. J. Wound Care 2011, 20 (11), 543-549.

[96] Gordon, N. C.; Wareham, D. W. Antimicrobial Activity of the Green Tea Polyphenol (-)-Epigallocatechin-3-Gallate (EGCG) against Clinical Isolates of Stenotrophomonas Maltophilia. Int. $J$. Antimicrob. Agents 2010, 36 (2), 129-131.

[97] Sood, A.; Granick, M. S.; Tomaselli, N. L. Wound Dressings and Comparative Effectiveness Data. Adv. wound care 2014, 3 (8), 511-529.

[98] He, S.; J. Yaszemski, M.; Yasko, A. W.; Engel, P. S.; Mikos, A. G. Injectable Biodegradable Polymer Composites Based on Poly(propylene Fumarate) Crosslinked with Poly(ethylene Glycol)-Dimethacrylate. Biomaterials 2000, 21 (23), 2389-2394.

[99] Koetting, M. C.; Peters, J. T.; Steichen, S. D.; Peppas, N. A. Stimulus-Responsive Hydrogels: Theory, Modern Advances, and Applications. Mater. Sci. Eng. R Reports 2015, 93, 1-49.

[100] Gupta, P.; Vermani, K.; Garg, S. Hydrogels: From Controlled Release to $\mathrm{pH}$-Responsive Drug Delivery. Drug Discovery Today, 2002, 7, 569-579.

[101] Qu, X.; Wirsén, A.; Albertsson, A. C. Novel pH-Sensitive Chitosan Hydrogels: Swelling Behavior and States of Water. Polymer (Guildf). 2000, 41 (12), 4589-4598.

[102] Klouda, L. Thermoresponsive Hydrogels in Biomedical Applications A Seven-Year Update. European Journal of Pharmaceutics and Biopharmaceutics, 2015, 97, 338-349.

[103] Liu, R.; Fraylich, M.; Saunders, B. R. Thermoresponsive Copolymers: From Fundamental Studies to Applications. Colloid and Polymer Science, 2009, 287, 627-643.

[104] Meenach, S. A.; Anderson, K. W.; Hilt, J. Z. Synthesis and Characterization of Thermoresponsive Poly[ethylene Glycol]Based Hydrogels and Their Magnetic Nanocomposites. J. Polym. Sci. Part A Polym. Chem. 2010, 48 (15), 3229-3235.

[105] Rzaev, Z. M. O.; Dinçer, S.; Pişkin, E. Functional Copolymers of N-Isopropylacrylamide for Bioengineering Applications. Progress in Polymer Science (Oxford), 2007, 32, 534-595.

[106] da Silva, R.; Ganzarolli de Oliveira, M. Effect of the CrossLinking Degree on the Morphology of poly(NIPAAm-Co-AAc) Hydrogels. Polymer (Guildf). 2007, 48 (14), 4114-4122.

[107] Banerjee, I.; Mishra, D.; Das, T.; Maiti, T. K. Wound pHResponsive Sustained Release of Therapeutics from a Poly(NIPAAm-Co-AAc) Hydrogel. J. Biomater. Sci. Polym. Ed. 2012, 23 (1-4), 111-132.

[108] Nguyen, M. K.; Park, D. K.; Lee, D. S. Injectable
Poly(amidoamine)-Poly(ethylene Glycol)-Poly(amidoamine) Triblock Copolymer Hydrogel with Dual Sensitivities: $\mathrm{pH}$ and Temperature. In Biomacromolecules; 2009; Vol. 10, pp 728-731.

[109] Van Doren, S. R. Matrix Metalloproteinase Interactions with Collagen and Elastin. Matrix Biol. 2015, 44-46, 224-231.

[110] Lutolf, M. P.; Lauer-Fields, J. L.; Schmoekel, H. G.; Metters, a T.; Weber, F. E.; Fields, G. B.; Hubbell, J. a. Synthetic Matrix Metalloproteinase-Sensitive Hydrogels for the Conduction of Tissue Regeneration: Engineering Cell-Invasion Characteristics. Proc. Natl. Acad. Sci. U. S. A. 2003, 100 (9), 5413-5418.

[111] Patterson, J.; Hubbell, J. A. Enhanced Proteolytic Degradation of Molecularly Engineered PEG Hydrogels in Response to MMP-1 and MMP-2. Biomaterials 2010, 31 (30), 7836-7845.

[112] Lorentz, K. M.; Kontos, S.; Frey, P.; Hubbell, J. A. Engineered Aprotinin for Improved Stability of Fibrin Biomaterials. Biomaterials 2011, 32 (2), 430-438.

[113] Martino, M. M.; Tortelli, F.; Mochizuki, M.; Traub, S.; BenDavid, D.; Kuhn, G. a; Müller, R.; Livne, E.; Eming, S. a; Hubbell, J. a. Engineering the Growth Factor Microenvironment with Fibronectin Domains to Promote Wound and Bone Tissue Healing. Sci. Transl. Med. 2011, 3 (100), 100ra89.

[114] St John, A.; Price, C. P. Existing and Emerging Technologies for Point-of-Care Testing. Clin. Biochem. Rev. 2014, 35 (3), 155-167.

[115] Nakagami, G.; Sanada, H.; Iizaka, S.; Kadono, T.; Higashino, T.; Koyanagi, H.; Haga, N.; Care, W. Predicting Delayed Pressure Ulcer Healing Using Thermography: A Prospective Cohort Study. J. Wound Care 2010, 19 (11), 465-472.

[116] Matzeu, G.; Losacco, M.; Parducci, E.; Pucci, A.; Dini, V.; Romanelli, M.; Di Francesco, F. Skin Temperature Monitoring by a Wireless Sensor. IECON 2011 - 37th Annu. Conf. IEEE Ind. Electron. Soc. 2011, 3533-3535.

[117] Segal, E.; Perelman, L. A.; Cunin, F.; Di Renzo, F.; Devoisselle, J. M.; Li, Y. Y.; Sailor, M. J. Confinement of Thermoresponsive Hydrogels in Nanostructured Porous Silicon Dioxide Templates. Adv. Funct. Mater. 2007, 17 (7), 1153-1162.

[118] Wu, J.; Sailor, M. J. Chitosan Hydrogel-Capped Porous SiO2 as a $\mathrm{pH}$ Responsive Nano-Valve for Triggered Release of Insulin. Adv. Funct. Mater. 2009, 19 (5), 733-741.

[119] Sciacca, B.; Secret, E.; Pace, S.; Gonzalez, P.; Geobaldo, F.; Quignard, F.; Cunin, F. Chitosan-Functionalized Porous Silicon Optical Transducer for the Detection of Carboxylic AcidContaining Drugs in Water. Journal of Materials Chemistry, 2011, 21, 2294.

[120] Vasani, R. B.; McInnes, S. J. P.; Cole, M. A.; Jani, A. M. M.; Ellis, A. V.; Voelcker, N. H. Stimulus-Responsiveness and Drug Release from Porous Silicon Films ATRP-Grafted with poly(NIsopropylacrylamide). Langmuir 2011, 27 (12), 7843-7853.

[121] Romanelli, M.; Dini, V.; Barbanera, S.; Bertone, M. S. Evaluation of the Efficacy and Tolerability of a Solution Containing Propyl Betaine and Polihexanide for Wound Irrigation. Skin Pharmacol. Physiol. 2010, 23 (SUPPL. 1), 41-44.

[122] Schneider, L. A.; Korber, A.; Grabbe, S.; Dissemond, J. Influence of $\mathrm{pH}$ on Wound-Healing: A New Perspective for WoundTherapy? Archives of Dermatological Research, 2007, 298, 413420.

[123] Sridhar, V.; Takahata, K. A Hydrogel-Based Passive Wireless Sensor Using a Flex-Circuit Inductive Transducer. Sensors Actuators, A Phys. 2009, 155 (1), 58-65.

[124] Schreml, S.; Meier, R. J.; Wolfbeis, O. S.; Landthaler, M.; Szeimies, R.-M.; Babilas, P. 2D Luminescence Imaging of $\mathrm{pH}$ in Vivo. Proc. Natl. Acad. Sci. U. S. A. 2011, 108, 2432-2437.

[125] Tamayol, A.; Akbari, M.; Zilberman, Y.; Comotto, M.; Lesha, E.; Serex, L.; Bagherifard, S.; Chen, Y.; Fu, G.; Ameri, S. K.; et al. Flexible $\mathrm{pH}$-Sensing Hydrogel Fibers for Epidermal Applications. Adv. Healthc. Mater. 2016, 5 (6), 711-719.

[126] World Union of Wound Healing Societies. Principles of Best Practice: Diagnostics and Wounds. A Consensus Document; 2008.

[127] Hajnsek, M.; Schiffer, D.; Harrich, D.; Koller, D.; Verient, V.; Palen, J. V. D.; Heinzle, A.; Binder, B.; Sigl, E.; Sinner, F.; et al. An Electrochemical Sensor for Fast Detection of Wound Infection Based on Myeloperoxidase Activity. Sensors Actuators, B Chem. 
2015, 209, 265-274.

[128] Schiffer, D.; Blokhuis-Arkes, M.; Van Der Palen, J.; Sigl, E.; Heinzle, A.; Guebitz, G. M. Assessment of Infection in Chronic Wounds Based on the Activities of Elastase, Lysozyme and Myeloperoxidase. British Journal of Dermatology, 2015, 173, 1529-1531.

[129] Ferreira, A. V.; Perelshtein, I.; Perkas, N.; Gedanken, A.; Cunha, J.; Cavaco-Paulo, A. Detection of Human Neutrophil Elastase [HNE] on Wound Dressings as Marker of Inflammation. Appl. Microbiol. Biotechnol. 2017, 101 (4), 1443-1454.

[130] Tegl, G.; Schiffer, D.; Sigl, E.; Heinzle, A.; Guebitz, G. M. Biomarkers for Infection: Enzymes, Microbes, and Metabolites. Applied Microbiology and Biotechnology, 2015, 99, 4595-4614.

[131] Blokhuis-Arkes, M. H. E.; Haalboom, M.; Van Der Palen, J.; Heinzle, A.; Sigl, E.; Guebitz, G.; Beuk, R. Rapid Enzyme Analysis as a Diagnostic Tool for Wound Infection: Comparison between Clinical Judgment, Microbiological Analysis, and Enzyme Analysis. Wound Repair Regen. 2015, 23 (3), 345-352. Serena, T. E. Development of a Novel Technique to Collect Proteases from Chronic Wounds. Adv. Wound Care 2014, 3 (2), 729-732.

[133] Gao, L.; Mbonu, N.; Cao, L.; Gao, D. Label-Free Colorimetric Detection of Gelatinases on Nanoporous Silicon Photonic Films. Anal. Chem. 2008, 80 (5), 1468-1473.

[134] Stair, J. L.; Watkinson, M.; Krause, S. Sensor Materials for the Detection of Proteases. Biosens. Bioelectron. 2009, 24 (7), 21132118.
Hasmann, A.; Gewessler, U.; Hulla, E.; Schneider, K. P.; Binder, B.; Francesko, A.; Tzanov, T.; Schintler, M.; Van der Palen, J.; Guebitz, G. M.; et al. Sensor Materials for the Detection of Human Neutrophil Elastase and Cathepsin G Activity in Wound Fluid. Exp. Dermatol. 2011, 20 (6), 508-513.

[136] Sadat Ebrahimi, M. M.; Voss, Y.; Schönherr, H. Rapid Detection of Escherichia Coli via Enzymatically Triggered Reactions in Self-Reporting Chitosan Hydrogels. ACS Appl. Mater. Interfaces 2015, 7 (36), 20190-20199.

[137] Hasmann, A.; Wehrschuetz-Sigl, E.; Kanzler, G. Novel Peptidoglycan-Based Diagnostic Devices for Detection of Wound Infection. Diagn Microbiol Infect Dis. 2011, 71(1),12-23.

[138] Schiffer, D.; Verient, V.; Luschnig, D.; Blokhuis-Arkes, M. H. E.; Palen, J. V. D.; Gamerith, C.; Burnet, M.; Sigl, E.; Heinzle, A.; Guebitz, G. M. Lysozyme-Responsive Polymer Systems for Detection of Infection. Eng. Life Sci. 2015, 15 (4), 368-375.

[139] Schneider, K. P.; Gewessler, U.; Flock, T.; Heinzle, A.; Schenk, V.; Kaufmann, F.; Sigl, E.; Guebitz, G. M. Signal Enhancement in Polysaccharide Based Sensors for Infections by Incorporation of Chemically Modified Laccase. N. Biotechnol. 2012, 29 (4), 502509. 